\title{
Sea ice detection with space-based LIDAR
}

\section{S. Rodier $^{1}$, Y. Hu${ }^{2}$, and M. Vaughan ${ }^{2}$}

${ }^{1}$ SSAI, NASA Langley Research Center, MS 475, Hampton VA 23681-2199, USA

${ }^{2}$ NASA Langley Research Center, MS 475, Hampton VA 23681-2199, USA

Received: 30 May 2013 - Accepted: 16 July 2013 - Published: 13 September 2013

Correspondence to: S. Rodier (sharon.d.rodier@nasa.gov)

Published by Copernicus Publications on behalf of the European Geosciences Union.

\section{Sea ice detection with space-based LIDAR}

\section{S. Rodier et al.}

\section{Title Page}

Abstract

Introduction

Conclusions

References

Tables

Figures

14

$\rightarrow 1$

Back

Close

\section{Full Screen / Esc}

Printer-friendly Version

Interactive Discussion 


\section{Abstract}

Monitoring long-term climate change in the Polar Regions relies on accurate, detailed and repeatable measurements of geophysical processes and states. These regions are among the Earth's most vulnerable ecosystems, and measurements there have 5 shown rapid changes in the seasonality and the extent of snow and sea ice coverage. The authors have recently developed a promising new technique that uses lidar surface measurements from the Cloud-Aerosol Lidar and Infrared Pathfinder Satellite Observations (CALIPSO) mission to infer ocean surface ice-water phase. CALIPSO's $532 \mathrm{~nm}$ depolarization ratio measurements of the ocean surface are uniquely capable of providing information about the ever-changing sea surface state within the Polar Regions. With the finer resolution of the CALIPSO footprint (90 $\mathrm{m}$ diameter, spaced $335 \mathrm{~m}$ apart) and its ability to acquire measurements during both daytime and nighttime orbit segments and in the presence of clouds, the CALIPSO sea ice product provides fine-scale information on mixed phase scenes and can be used to assess/validate the estimates of sea-ice concentration currently provided by passive sensors. This paper describes the fundamentals of the CALIPSO sea-ice detection and classification technique. We present retrieval results from a six-year study, which are compared to existing data sets obtained by satellite-based passive remote sensors.

\section{Introduction}

20 Much work in recent years has been dedicated to tracking the Earth's decreasing ice cover. As reported in the 2012 Arctic Report Card (Perovich et al., 2012), the Arctic experienced the largest recorded loss of sea ice extent from March to September of 2012. Historically, the month of March is when the maximum sea-ice extent is reached and September being the minimum. By the end of the recent summer melt season satellite records (active since 1979) indicated that September 2012 ice extent was the lowest observed, falling $49 \%$ below the 1979-2000 average minimum (Perovich et al.,
Sea ice detection with space-based LIDAR

S. Rodier et al.

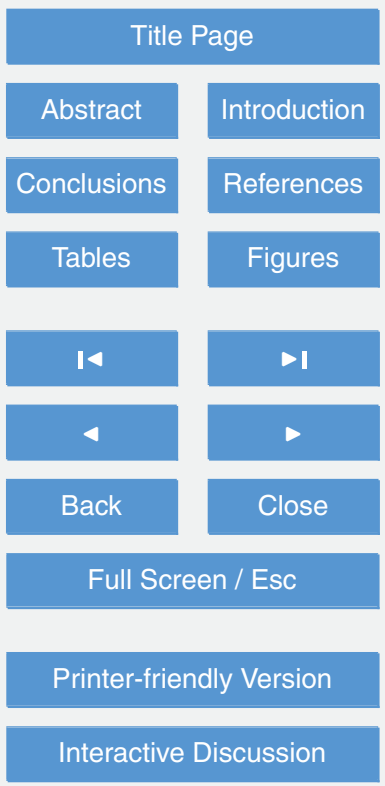


2012). With increased ice melt, a transition towards a thinner, younger ice cover is occurring (e.g., Kwok, 2007; Maslanik et al., 2007), and the formation of melt ponds on first-year sea ice reduces its albedo and increases the solar energy input and melt rate of the underlying ice (Polashenski, et al., 2008). At the end of summer 2011, 5 only $25 \%$ of the Arctic sea ice was more than two years old, compared to $50-60 \%$ during the 1980s (Stroeve et al., 2012). Almost none of the oldest and thickest ice (at least five years old) remains (3\% in February 2012 compared to $30-40 \%$ in the 1980s) (e.g., Francis and Vavrus, 2012). This shift from a multiyear to seasonal ice cover has significant implications for the heat and mass budget of the ice and for the 10 Artic ecosystems.

Since launching in April 2006, the principal objective of the Cloud-Aerosol Lidar and Infrared Pathfinder Satellite Observations (CALIPSO) mission has been studying the climate impact of clouds and aerosols in the atmosphere (Winker et al., 2010). The primary instrument aboard CALIPSO is CALIOP (i.e., the Cloud Aerosol Lidar with Orthogonal Polarization), a two-wavelength $(532 \mathrm{~nm}$ and $1064 \mathrm{~nm}$ ) polarizationsensitive (at $532 \mathrm{~nm}$ ) elastic backscatter lidar (Hunt et al., 2009). Recent work by Rodier et al. (2012) has demonstrated that, in addition to the cloud and aerosol parameters that make up CALIOP's standard suite of data products (Winker et al., 2009), the CALIOP daytime and nighttime measurements can also be used to infer ocean surface ice-water phase. Numerous studies have shown that lidar backscattering depolarization measurements can be used to distinguish between liquid and solid phases of water in the atmosphere (Sassen, 1991; Intrieri et al., 2002; Hu et al., 2009). In this study the depolarization ratio, $\delta$, is defined as $\delta=\beta_{\perp} / \beta_{\|}$, where $\beta_{\perp}$ and $\beta_{\|}$are the are the backscatter intensities measured with respect to the polarization plane of the 25 linearly polarized laser transmitter (Alvarez et al., 2006). The parallel (\|) component of the backscatter retains its original polarization state, while the so-called perpendicular $(\perp)$ component does not (Gimmestad, 2008). Here, analyses of collocated CALIPSO $532 \mathrm{~nm}$ ocean surface depolarization ratios and Advanced Microwave Scanning Radiometer - Earth Observing System (AMSR-E) $12 \mathrm{~km}$ resolution ice concentrations
TCD

7, 4681-4701, 2013

Sea ice detection

with space-based LIDAR

S. Rodier et al.

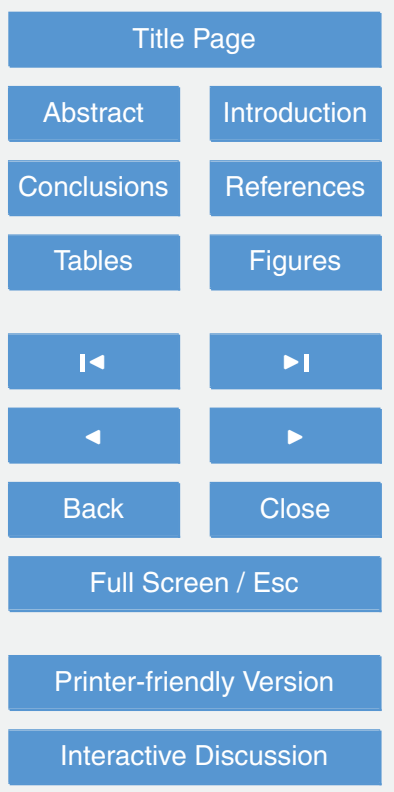


provide strong evidence for this relationship between surface echo depolarization and surface ice-water state. Seasonal variability of sea ice concentration and ice extent has been monitored by many of the A-Train satellites such as the AMSR-E, and the Moderate-resolution Imagining Spectroradiometer (MODIS). The finer resolution of the 5 CALIPSO footprints ( $90 \mathrm{~m}$ diameter, spaced $335 \mathrm{~m}$ apart) and its ability to retrieve surface ice-water phase beneath moderate cloud cover (optical depths $<3$ ) can provide detailed insights into sea ice formation and dissipation that will allow more accurate interpretation of the existing data sets, especially during the during the season transition months. Because CALIPSO's measurements are not limited to daytime or clear - sky conditions, the CALIPSO sea ice product can provide "fill-in" measurements where other data products are limited due to instrument characteristics or have the practice of masking land surfaces. Prediction models may also benefit from the finer resolution in discriminating ice boundaries.

\section{Retrieval methodology}

When the CALIPSO orbit transects surfaces covered by ice, be it land or ocean, the backscattered signal intensity from the surface is very strong and will frequently cause digitizer saturation. This response will be very evident in the two $532 \mathrm{~nm}$ channels (parallel and perpendicular) at and immediately below the Earth's surface. When the signals from these channels are ratioed, the resulting depolarization values are in the 20 range of $0.55-1.1$. Conversely, when CALIPSO transects surfaces covered by water, the signal intensity is substantially reduced, most especially in the perpendicular channel, and the resulting depolarization values typically lie between 0.0-0.2. As illustrated in Fig. 1, it is this specific effect that enables the $532 \mathrm{~nm}$ depolarization data to be used for ice classification purposes. The left column of Fig. 1b, c, and d illustrates the measured backscatter from an ice surface. Each image shows a small section of the nighttime orbit over the Arctic starting at $77^{\circ} \mathrm{N}$ and descending to $73^{\circ} \mathrm{N}$ on $14 \mathrm{De}-$ cember 2010 between 17:25 and 17:30 UTC. The altitude range includes attenuated
TCD

Sea ice detection with space-based LIDAR

S. Rodier et al.

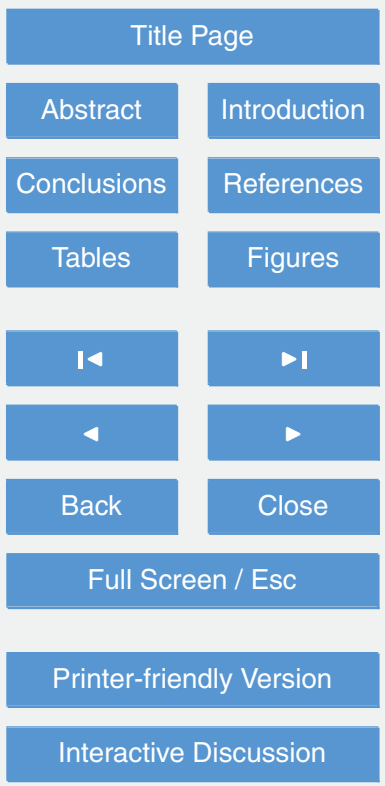


backscatter from $2 \mathrm{~km}$ below the surface to $15 \mathrm{~km}$ above the surface. In each of the images the estimated surface elevation, derived from a digital elevation map, is displayed as a red line. Surrounding this red line, the saturated values appear as multi-layered "ribbon". The attenuated backscatter samples from this "ribbon" section will be used 5 in the global assessment of ocean surface ice-water phase study. The right column of Fig. 1d, e, and f illustrates a water transect with a section of ascending daytime orbit starting at $-49^{\circ} \mathrm{S}$ to $-24^{\circ} \mathrm{S}$ from 14 December 2010 between 13:30 and 13:35 UTC. The differences in measured surface depolarization due to surface type are clearly seen in images $\mathrm{d}$ and $\mathrm{h}$ : the polar icecaps measured in image $\mathrm{d}$ show surface depo10 larization ratios well in excess of 0.6 (actual values are $0.747 \pm 0.0425$ ), whereas the depolarization ratios in the subtropical open ocean shown in image $\mathrm{h}$ are uniformly below 0.1 (actual values are $0.024 \pm 0.028$ ). Also illustrated in Fig. $1 \mathrm{~b}, \mathrm{c}$ and $\mathrm{d}$ is an example of the non-ideal transient recovery of the $532 \mathrm{~nm}$ detectors due to very strong signal returns. In extreme cases, the non-ideal transient recovery can make it wrongly 15 appear as if the laser signal is penetrating the surface to a depth of several hundreds of meters (McGill et al., 2007). Because identical detectors with essentially identical transient recovery behaviors are used on both $532 \mathrm{~nm}$ channels, highly reflective ice surfaces readily induce non-ideal transient responses in both $532 \mathrm{~nm}$ signal returns (Hunt et al., 2009). On the other hand, the darker, less reflective water surfaces (e.g., see Fig. 1f, $g$ and $h$ ) generate substantially weaker backscatter returns, and thus the effects of this non-ideal recovery are reduced to a negligible level.

The $532 \mathrm{~nm}$ depolarized surface return is not reported in the existing CALIPSO data products, but instead is derived from the detected CALIOP surface echo every $335 \mathrm{~m}$ along track. The CALIOP surface detection algorithm (Vaughan et al., 2009) uses the Global 30 Arc-Second Elevation Data Set (GTOPO30; see http://eros.usgs.gov/\#/ Find_Data/Products_and_Data_Available/GTOPO30) digital elevation map (DEM) as the starting point in its search for the lidar surface echo. Whenever the ocean surface is detected, the altitudes of the top and the base of the surface echo are stored in and can be retrieved from the Level 2 CALIPSO layer data products. In our studies to date,

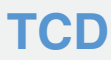

$7,4681-4701,2013$

\section{Sea ice detection with space-based LIDAR \\ S. Rodier et al.}

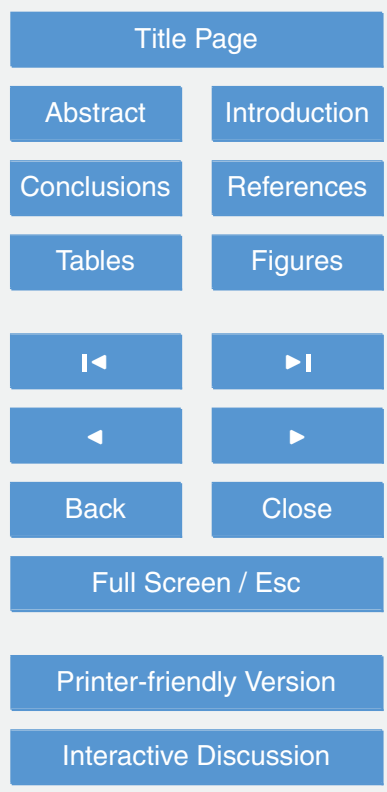


the top and base altitudes have been retrieved from the Level $2335 \mathrm{~m}$ Cloud Layer product, which is the highest resolution product produced by the CALIPSO team. We then inspect the corresponding Level 1 attenuated backscatter profile product, and retrieve the range-resolved $532 \mathrm{~nm}$ parallel $\left(\beta_{\|}(z)\right)$ and perpendicular $\left(\beta_{\perp}(z)\right)$ attenuated 5 backscatter measurements from two consecutive altitude bins above the top altitude of the surface spike to five altitude bins below the base of the surface spike, thereby compensating for possible detection errors in the CALIPSO standard algorithm and/or GTOPO30. These data are screened for fill values, integrated and ratioed, creating a surface integrated depolarization ratio, defined as follows:

$10 \quad \delta_{\text {surface }}=\sum_{k=\text { top }}^{\text {base }} \beta_{\perp}\left(z_{k}\right) / \sum_{k=\text { top }}^{\text {base }} \beta_{\|}\left(z_{k}\right)$

When harvesting the Level 1 data, additional surface properties such as DEM altitude, International Geosphere/Biosphere Programme (IGBP) surface classification and National Snow and Ice Data Center (NSIDC) snow and ice coverage (re-averaged to CERES footprint $\sim 30 \mathrm{~km}$ ) are retrieved as references. To quantify signal attenuation

\section{Assessment of the CALIPSO lidar surface return classification technique}

Initial verification that the CALIPSO depolarization surface returns can be used to discriminate surface ice-water phase requires that each measured depolarization ratio be compared to a product that specializes in ice classification. We therefore have collocated each of the $335 \mathrm{~m}$ CALIPSO $532 \mathrm{~nm}$ depolarization measurements to the AMSRE $12 \mathrm{~km}$ Level-3 gridded daily product AE_SI12. The colocation was achieved via a two-step process (Nagle and Holz, 2009). Data was first collocated in time, and then in space. The CALIOP position information was used to find the best matching AMSR-E 4686 
pixel. Once a match was found, a location offset from the CALIOP footprint was calculated and stored. Only samples with a longitude offset less than $0.11^{\circ}$ (approximately $12 \mathrm{~km}$ ) were included in the retrieval. The AE_SI12 product includes daily averages for sea ice concentrations and snow depth over sea ice at a $12.5 \mathrm{~km}$ spatial resolution 5 (Comiso et al., 2003). From the AMSR-E data, the ice concentration, ice concentration uncertainties, and snow depth are retrieved for comparative analysis and validation. The comparison data set was restricted to include only those calculated depolarization ratios between 0.0 and 1.2 for which the location of the CALIPSO footprint was within the bounds of the $12 \mathrm{~km}$ AMSR-E pixel. This consisted of 29,7679 034 samples for the 10 Northern Latitudes, for which $99 \%$ of the depolarization ratios were between 0.0 and 1.2. Depolarization values normally do not exceed 1.0 unless the detectors receive a very strong signal return.

As an initial test of our concept we constructed a histogram using all $532 \mathrm{~nm}$ depolarization measurements that were collocated with AMSR-E classifications during 15 2010. All collocated samples classified by AMSR-E as water, open water, or ice with an ice concentration greater than $30 \%$ were retrieved and tested. Figure 2 illustrates a distinctive bimodal histogram with distributions from 0.0 to 0.2 and 0.55 to 1.1. Upon examination, we found that pixels classified as water by AMSR-E correlated to depolarization ratios in the range of 0.0 to 0.2 at a rate of $95.2 \%$, and pixels classified as ice correlated to depolarization ratios in the range of 0.55 to 1.1 at a rate of $98.0 \%$.

\subsection{Northern Hemisphere analysis}

Using this newly-defined ice and water classification criteria, samples from July 2006 through September 2011 (i.e., the time period when CALIPSO and AMSR-E had coincidental measurements) were retrieved and grouped for additional testing. Each depolarization value was compared to its collocated AMSR-E pixel classification, generating statistics for tracking the level of agreement for this classification methodology. First we looked at the consistency of the ice classification for samples in the northern latitudes. As seen in Fig. 3, a seasonal trend is evident with the higher percentage of agreement

Sea ice detection with space-based LIDAR

S. Rodier et al.

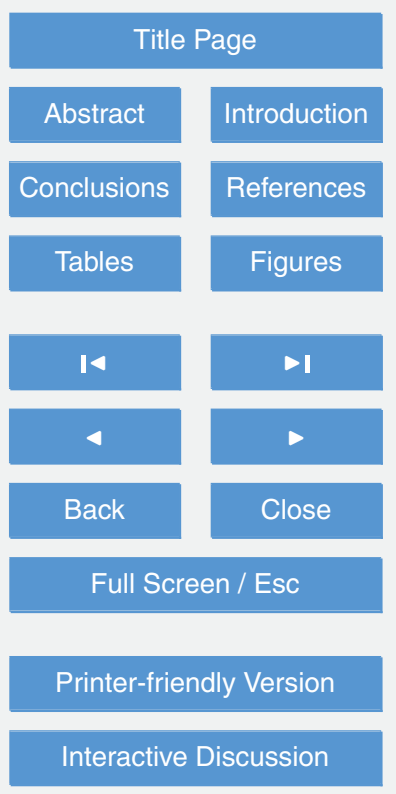


in the winter months and a lower percentage of agreement in the transitional summerfall months. For 61 of the 63 months of our data sample, when AMSR-E classified the pixel as ice, the calculated depolarization values fell in the range of 0.55 to 1.1 at a rate of $90 \%$ or higher. The two months that did not measure above $90 \%$ agreement 5 were August 2007, when the rate was $89.2 \%$, and September 2011, when the rate was $89.5 \%$.

Next we looked at the consistency of the water classification for samples in the northern latitudes. As seen in Fig. 4, a seasonal trend is also evident, with a higher percentage of agreement in the winter months and a lower percentage of agreement in the 10 summer months. For 51 of the 63 months, when AMSR-E classified the pixel as water, the calculated depolarization values fell in the range of 0.0 to 0.2 at a rate of $90 \%$ or higher. For 60 of the 63 months the agreement was $85 \%$ or higher. The summer months, specifically June and July 2007 through 2011 showed the lowest agreement.

Though the summer and transitional months recorded the lowest percentage of 15 scene classification agreement for both of the two classification test cases, it does highlight the possibility of CALIPSO's depolarization values providing fractional scene classification. A maximum of 36 CALIPSO $335 \mathrm{~m}$ surface depolarization samples could fall within each $12 \mathrm{~km}$ AMRS-E pixel and provide additional information about sea surface classification. When examining the collocated records that indicated a mismatch for ice classification, it was found that $85 \%$ of those records contain AMSR-E pixels with ice concentrations in the range of $10 \%$ to $80 \%$ indicating a mix-phase scene of ice and water. When examining the non-matching collocated records for water classification it was found that $80 \%$ of those records also contained ice concentrations in the range of $10 \%$ to $80 \%$. The non-matching due to a mixed-phase scene was not unexpected. In this study our scene matching criteria required $100 \%$ agreement between the classification reported by AMSR-E and the newly-defined CALIPSO ice and water classification. It would not be expected that each of the $335 \mathrm{~m}$ CALIPSO samples collocated with a $12 \mathrm{~km}$ AMSR-E pixel have $100 \%$ scene classification agreement, especially during the summer and transitional months.
TCD

7, 4681-4701, 2013

Sea ice detection

with space-based LIDAR

S. Rodier et al.

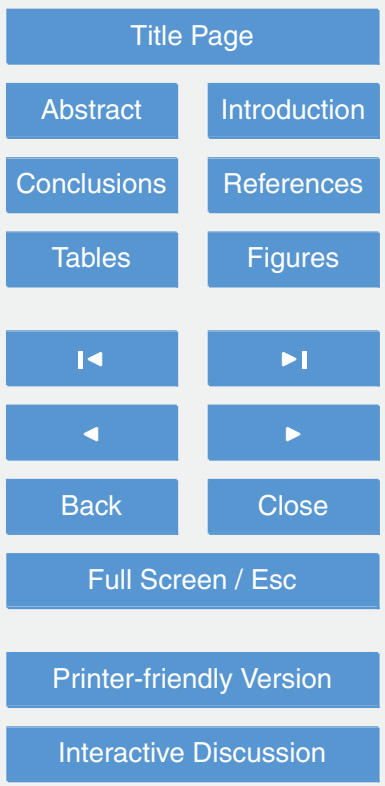


Additional analysis was performed to determine if cloud cover contributed to the mismatch in scene classification. Data from the October 2009 ice classification data set was selected for the initial test. Of the 805656 valid collocated samples in this subset, $94 \%$ showed agreement between the CALIPSO and AMSR-E scene classifications. $540 \%$ of these matching scenes contain one or more cloud layers, whereas $60 \%$ of the matching scenes were classified as clear sky. The remaining $6 \%$ of October 2009 ice classification valid samples had been classified as non-matching with $68 \%$ having clear sky and $31 \%$ having one or more cloud layers. Table 1 lists the percentages of cloudy and clear sky samples for each month of 2009.

10 The similar distributions of cloudy and clear sky samples for the matching and nonmatching ice classification scenes seen in Table 1 strongly suggest that clouds do not contribute to the mismatch in scene classification.

From our analysis, the prevailing reason for a mismatch in the scene classification is not due to cloud cover, but instead from attempting to match a $335 \mathrm{~m}$ CALIPSO sample 15

pinpoint the locations of pockets of water (newly formed melt ponds) in AMSR-E pixels classifies as ice (or, conversely, to locate chunks of ice in pixels that AMSR-E classifies as water) is illustrated in the July 2011 Artic circle plots (Fig. $5 a$ and b).

Figure 5a represents the CALIOP footprints for July 2011 with depolarization values 20 less than 0.2, and thus classified as water. Figure $5 \mathrm{~b}$ is the AMSRE classification for the collocated pixel. The AMSRE plot ranges from $100 \%$ ice, seen in dark red, to zero percent ice, or water, which is represented as white. Of interest is the area between $120^{\circ} \mathrm{W}$ to $120^{\circ} \mathrm{E}$ where AMSRE indicates $90-100 \%$ ice and CALIOP has detected water. CALOIP's detection ability would be an asset to the community for uncertainty

\subsection{Southern Hemisphere analysis}

Next we looked at the consistency of the ice classification for samples in the southern latitudes. As seen in Fig. 6, a seasonal trend is evident with the higher percentage of

Sea ice detection with space-based LIDAR

S. Rodier et al.

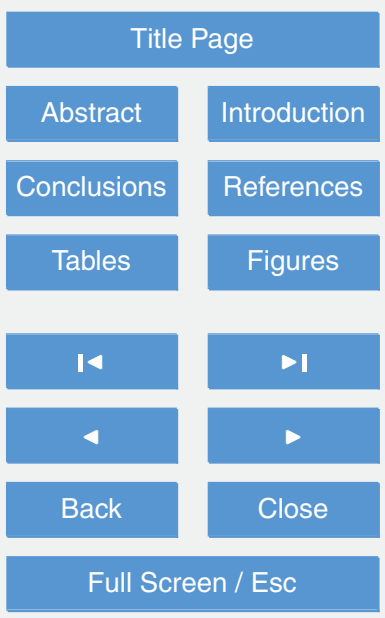

Printer-friendly Version

Interactive Discussion 
agreement in the winter months and a slightly lower percentage of agreement for the summer months of January and February. For 58 of the 63 months of our data sample, when AMSR-E classified the pixel as ice, the calculated depolarization values fell in the range of 0.55 to 1.1 at a rate of $90 \%$ or higher. However February 2007, 2009, 2010, 52011 and January 2011, all austral summer months, had an agreement between $88 \%$ and $89 \%$.

A seasonal trend is also evident when analyzing the agreement for water classifications Fig. 7. a higher percentage of agreement is seen in the winter months and again a lower percentage of agreement for the summer months. For 37 of the 63 months, 10 when AMSR-E classified the pixel as water, the calculated depolarization values fell in the range of 0.0 to 0.2 at a rate of $90 \%$ or higher. For 58 of the 63 months the agreement was $85 \%$ or higher. The season transition months, specifically November 2006 through 2011 showed the lowest agreement.

\subsection{Water verification}

15 Additional verification of the depolarization range for water classification was performed by selecting all data samples for July 2010 between latitude bands 20 north-20 south and grouping them by the International Geosphere/Biosphere Programme (IGBP) (water) and the SDP Toolkit/HDF-EOS Land-Water Mask subtypes for analysis. 3783330 samples were classified by IGBP as water and $99.83 \%$ of these had depolarization 20 ratios between 0.0 and 0.21 with a mean value of 0.012 and a standard deviation of 0.014 . The $0.16 \%$ of samples that fell outside of the expect range were located along three longitude bands (100W, 50E and 150E) where the IGBP footprint overlaid a coastal region.
TCD

$7,4681-4701,2013$

Sea ice detection

with space-based

LIDAR

S. Rodier et al.

Title Page 


\section{Summary}

In this paper we describe a new application of the CALIPSO $532 \mathrm{~nm}$ attenuated backscatter data to provide additional observations in the Polar Regions. We have shown that the retrieval of the $532 \mathrm{~nm}$ surface depolarization provides an accurate

5 classification of the sea surface scenes. This retrieval can be performed with samples acquired during the CALIPSO day and nighttime orbits, and with samples that contain one or more cloud layers.

The AMSR-E $12 \mathrm{~km}$ L3 ice concentration data products provided the standard for our comparison of the newly defined CALIPSO surface ice-water classification technique.

10 After analyzing 63 months of collocated samples we found that our method accurately classified the surface scene at a rate of $90 \%$ or higher. We note that our success rate had a seasonal variance, with a higher percentage of matching during the height of winter and lowest during the summer and transitional months. This trend was especially noticeable during the summer of 2007 when the arctic experienced one of the 15 largest melts in recent history. We believe that our scene classification methodology produced from the $335 \mathrm{~m}$ footprint could be an asset during these transitional months. The ability to detect the changing ice-water composition at a finer detail would provide an enhanced detailed scene composition. Additionally, with CALIPSO's measurements not being limited to daytime or clear sky conditions it could provide a "fill-in" measurement where other data products are limited due to instrument characteristics or have the practice of masking land surfaces. Prediction Models may also benefit from the finer resolution in discriminating ice boundaries.

\section{References}

Alvarez, J. M., Vaughan, M. A., Hostetler, C. A., Hunt, W. H., and Winker, D. M.: Calibration Technique for Polarization-Sensitive Lidars, J. Atmos. Oceanic Technol., 23, 683-699, doi:10.1175/JTECH1872.1, 2006.

Sea ice detection with space-based LIDAR

S. Rodier et al.

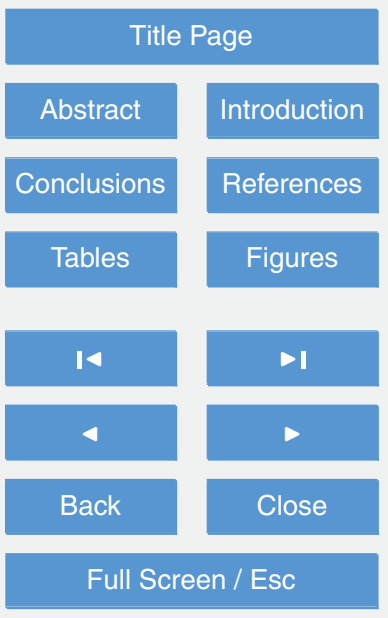

Printer-friendly Version

Interactive Discussion 
Comiso, J. C.: Warming trends in the Arctic from clear sky satellite observations, J. Climate, 16, 3498-3510, doi:10.1175/15200442(2003)016<3498:WTITAF>2.0.CO;2, 2003.

Francis, J. A. and Vavrus, S. J.: Evidence linking Arctic amplification to extreme weather in mid-latitudes, Geophys. Res. Lett., 39, L06801, doi:10.1029/2012GL051000, 2012.

5 Gimmestad, G. G.: Reexamination of depolarization in lidar measurements, Appl. Opt., 47, 3795-3802, doi:10.1364/AO.47.003795, 2008.

Hu, Y., Winker, D., Vaughan, M., Lin, B., Omar, A., Trepte, C., Flittner, D., Yang, P., Sun, W., Liu, Z., Wang, Z., Young, S., Stamnes, K., Huang, J., Kuehn, R., Baum, B., and Holz, R.: CALIPSO/CALIOP cloud phase discrimination algorithm, J. Atmos. Ocean. Techn., 26,

$10 \quad$ 2293-2309, doi:10.1175/2009JTECHA1280.1, 2009.

Hunt, W. H., Winker, D. M., Vaughan, M. A., Powell, K. A., Lucker, P. L., and Weimer, C.: CALIPSO lidar description and performance assessment, J. Atmos. Ocean. Tech., 26, 12141228, doi:10.1175/2009JTECHA1223.1, 2009.

Intrieri, J. M., Shupe, M. D., Uttal, T., and McCarty, B. J.: An annual cycle of Arctic 15 cloud characteristics observed by radar and lidar at SHEBA, J. Geophys. Res., 107, C7, doi:10.1029/2000JC000423, 2002.

Kwok, R.: Near zero replenishment of the Arctic multiyear sea ice cover at the end of 2005 summer, Geophys. Res. Lett., 34, L05501, doi:10.1029/2006GL028737, 2007.

Nagle, F. W. and Holz, R. E.: Computationally efficient methods of collocating satel20 lite, aircraft, and ground observations, J. Atmos. Ocean. Tech., 26, 1585-1595, doi:10.1175/2008JTECHA1189.1, 2009.

Maslanik, J. A., Fowler, C., Stroeve, J., Drobot, S., Zwally, J., Yi, D., and Emery, W.: a younger, thinner Arctic ice cover: increased potential for rapid, extensive sea-ice loss, Geophys. Res. Lett., 34, L24501, doi:10.1029/2007GL032043, 2007.

McGill, M. J., Vaughan, M. A., Trepte, C. R., Hart, W. D., Hlavka, D. L., Winker, D. M., and Kuehn, R.: Airborne validation of spatial properties measured by the CALIPSO lidar, J. Geophys. Res., 112, D20201, doi:10.1029/2007JD008768, 2007.

Nagle, F. W. and Holz, R. E.: Computationally efficient methods of collocating satellite, aircraft, and ground observations, J. Atmos. Ocean. Tech., 26, 1585-1595, doi:10.1175/2008JTECHA1189.1, 2009.

Perovich, D. K. and Polashenski, C.: Albedo evolution of seasonal Arctic sea ice, Geophys. Res. Lett., 39, L08501, doi:10.1029/2012GL051432, 2012a.

Sea ice detection with space-based LIDAR

S. Rodier et al.

Title Page 
Perovich, D. K. and Polashenski, C.: Albedo evolution of seasonal Arctic sea ice, Geophys. Res. Lett., 39, L08501, doi:10.1029/2012GL051432, 2012b.

Perovich, D., Meier, W., Tschudi, M., Gerland, S., and Richter-Meng, J.: Sea Ice (in Arctic Report Card 2012), available at: http://www.arctic.noaa.gov/reportcard, 2012.

5 Polashenski, C., Perovich, D., and Courville, Z.: The mechanisms of sea ice melt pond formation and evolution, J. Geophys. Res., 117, C01001, doi:10.1029/2011JC007231, 2012.

Rodier, S. D., Hu, Y.-X., and Vaughan, M. A.: CALIPSO surface return for ice and water detection, in: Reviewed and Revised Papers Presented at the 25th International Laser Radar Conference, edited by: Papayannis, A., Balis, D., and Amiridis, V., 801-804, 2012.

Sassen, K.: The polarization lidar technique for cloud research: a review and current assessment, B. Am. Meteorol. Soc., 72, 1848-1866, doi:10.1175/15200477(1991)072<1848:TPLTFC>2.0.CO;2, 1991.

Stroeve, J. C., Serreze, M. C., Holland, M. M., Kay, J. E., Malanik, J., and Barrett, A. P.: The Arctic's rapidly shrinking sea ice cover: a research synthesis, Climatic Change, 110, 100515 1027, doi:10.1007/s10584-011-0101-1, 2012.

Vaughan, M., Powell, K., Kuehn, R., Young, S., Winker, D., Hostetler, C., Hunt, W., Liu, Z., McGill, M., and Getzewich, B.: Fully automated detection of cloud and aerosol layers in the CALIPSO lidar measurements, J. Atmos. Ocean. Tech., 26, 2034-2050, doi:10.1175/2009JTECHA1228.1, 2009.

20 Winker, D. M., M. A. Vaughan, A. H. Omar, Y. Hu, K. A. Powell, Z. Liu, W. H. Hunt, and S. A. Young: "Overview of the CALIPSO Mission and CALIOP Data Processing Algorithms", J. Atmos. Oceanic Technol., 26, 2310-2323, doi:10.1175/2009JTECHA1281.1, 2009.

Winker, D. M., Pelon, J., Coakley Jr., J. A., Ackerman, S. A., Charlson, R. J., Colarco, P. R., Flamant, P., Fu, Q., Hoff, R., Kittaka, C., Kubar, T. L., LeTreut, H., McCormick, M. P., Megie, G., Poole, L., Powell, K., Trepte, C., Vaughan, M. A., and Wielicki, B. A.: The CALIPSO mission: a global 3D view of aerosols and clouds, B. Am. Meteorol. Soc., 91, 1211-1229, doi:10.1175/2010BAMS3009.1, 2010.

Sea ice detection

with space-based

LIDAR

S. Rodier et al.

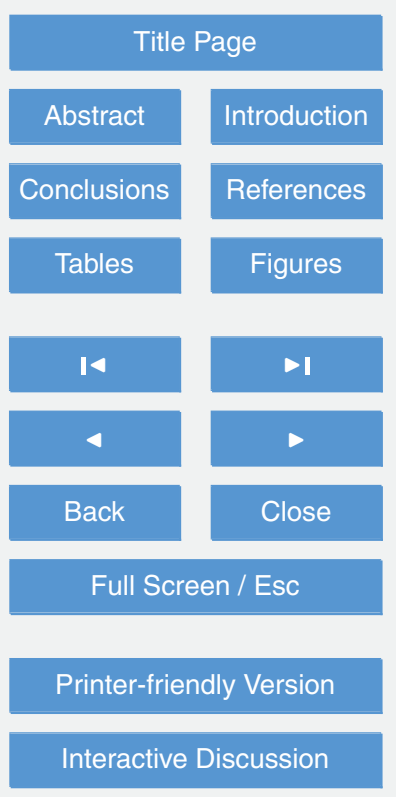


Table 1. The percentage of cloudy and clear sky samples for matching ice classification scenes and nonmatching ice classification scenes for each month of 2009.

\begin{tabular}{|c|c|c|c|c|c|c|c|}
\hline \multicolumn{2}{|l|}{2009} & \multicolumn{3}{|c|}{ Matching } & \multicolumn{3}{|c|}{ Non-matching } \\
\hline Month & $\begin{array}{r}\text { Total } \\
\text { samples }\end{array}$ & $\begin{array}{l}\text { Fraction } \\
\text { matching }\end{array}$ & $\begin{array}{l}\text { Cloudy } \\
\text { percent }\end{array}$ & $\begin{array}{r}\text { Clear } \\
\text { percent }\end{array}$ & $\begin{array}{r}\text { Fraction } \\
\text { non- } \\
\text { matching }\end{array}$ & $\begin{array}{l}\text { Cloudy } \\
\text { percent }\end{array}$ & $\begin{array}{r}\text { Clear } \\
\text { percent }\end{array}$ \\
\hline 01 & 2676542 & 98.84 & 26.02 & 74.98 & 1.16 & 27.56 & 72.44 \\
\hline 02 & 1595342 & .88 & 5 & 77.85 & 1.12 & 9.42 & 70.58 \\
\hline 03 & 1965518 & 99.09 & 16.69 & 83.31 & 0.91 & 28.4 & 71.55 \\
\hline 04 & 2821549 & 99.03 & 17.90 & 82.10 & 0.97 & 23.0 & 76.96 \\
\hline 05 & 1103272 & 97.75 & 27.42 & 72.58 & 2.25 & 18.43 & 81.57 \\
\hline 06 & 1008496 & 97.11 & 20.93 & 79.07 & 2.88 & 17.94 & 82.06 \\
\hline 07 & 810873 & 95.51 & 14.61 & 85.39 & 4.49 & 11.30 & 88.70 \\
\hline 08 & 356005 & 93.89 & 23.69 & 76.31 & 6.11 & 15.61 & 84.39 \\
\hline 09 & 367008 & 91.21 & 36.99 & 63.01 & 8.79 & 25.46 & 74.54 \\
\hline 10 & 805656 & 93.66 & 39.20 & 60.80 & 6.34 & 31.32 & 68.68 \\
\hline
\end{tabular}

\section{$7,4681-4701,2013$}

Sea ice detection with space-based LIDAR

S. Rodier et al.

\section{Title Page}

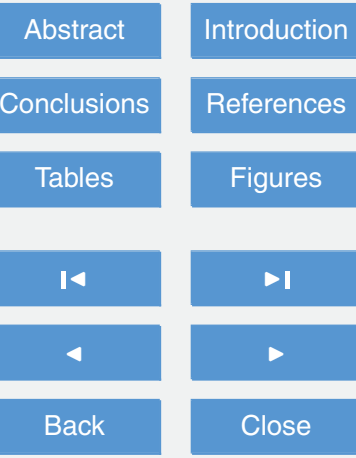

Full Screen / Esc

Printer-friendly Version

Interactive Discussion 


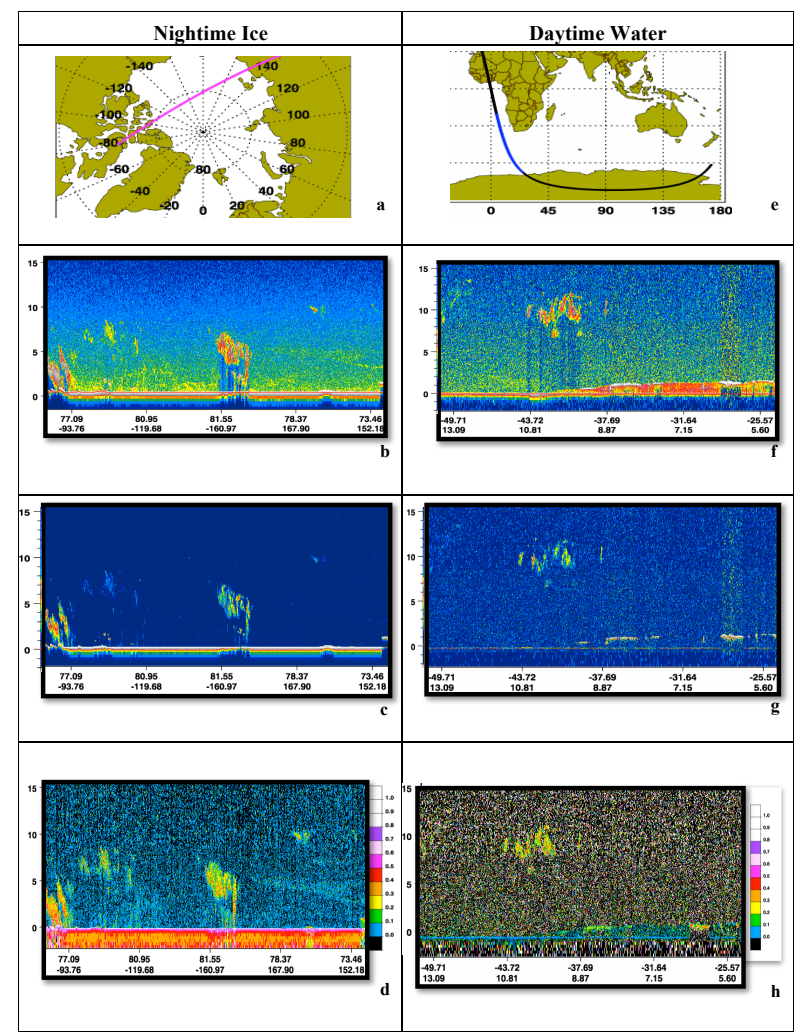

Fig. 1. (b and f) CALIOP $532 \mathrm{~nm}$ Total attenuated backscatter, (c and g) CALIOP $532 \mathrm{~nm}$ Perpendicular attenuated backscatter and (d and h) CALIOP $532 \mathrm{~nm}$ Depolarization Ratio.

\section{TCD}

$7,4681-4701,2013$

Sea ice detection with space-based LIDAR

S. Rodier et al.

Title Page

4

\section{Full Screen / Esc}

Printer-friendly Version

Interactive Discussion 


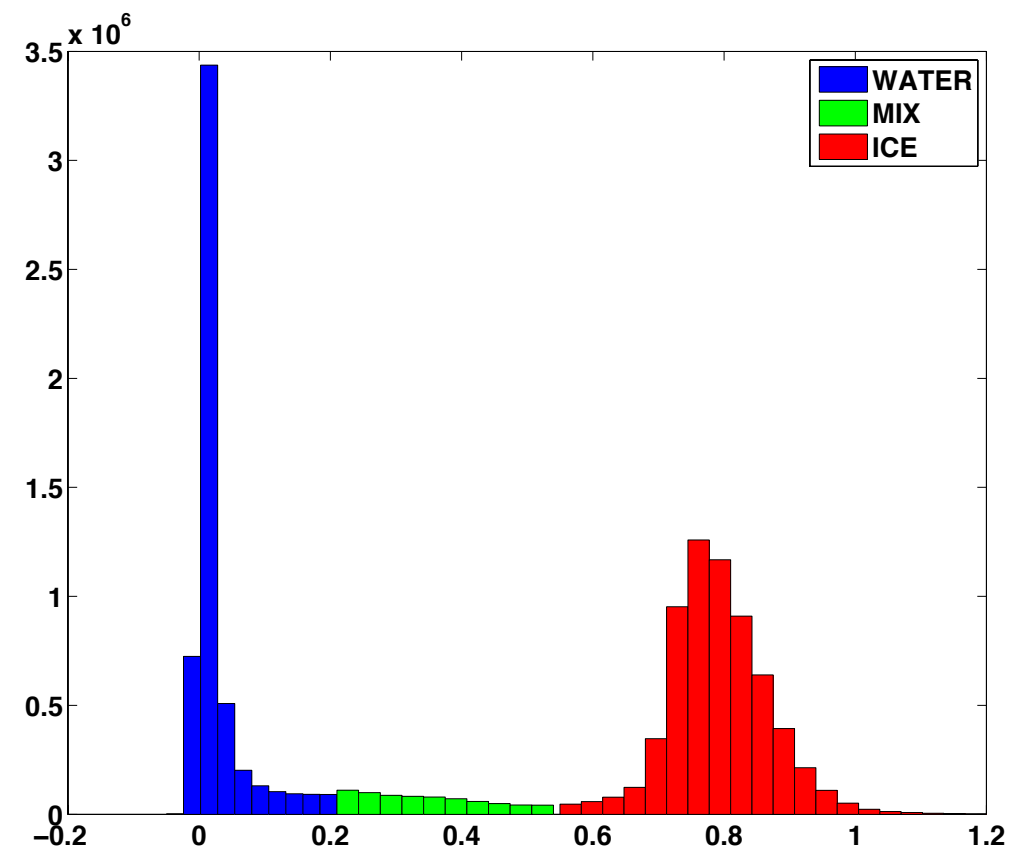

\section{Sea ice detection with space-based LIDAR}

S. Rodier et al.

Title Page

Abstract

Introduction

Conclusions

References

Tables

Figures

14

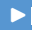

4

Back

$\checkmark$

Close

Full Screen / Esc

Printer-friendly Version

Interactive Discussion 


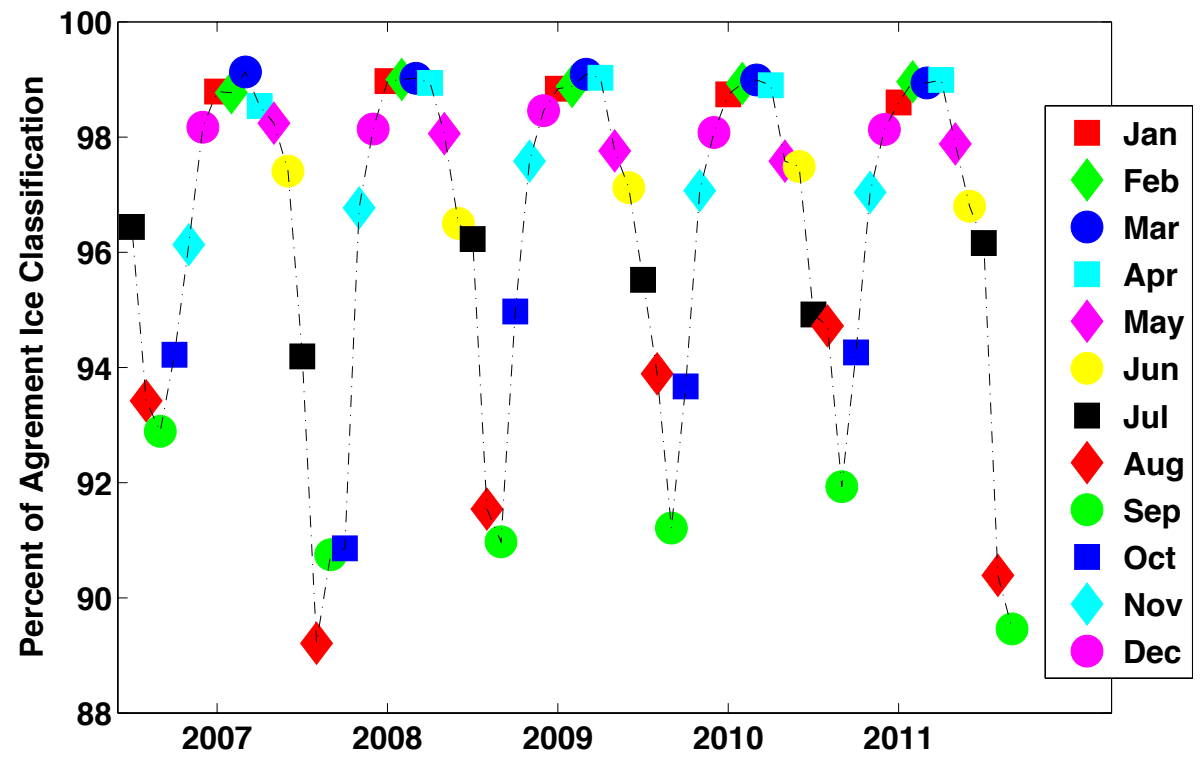

Fig. 3. Northern Latitudes for 2006 to 2011 monthly percentage of agreement when AMSR-E classified the pixel as ice, the calculated depolarization values fell in the range of 0.55 to 1.1.
TCD

$7,4681-4701,2013$

Sea ice detection with space-based LIDAR

S. Rodier et al.

Title Page

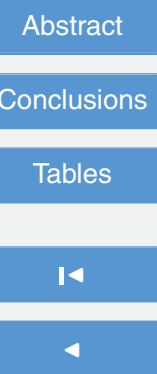

Back Introduction References Figures DI

$>$

Close

Full Screen / Esc

Printer-friendly Version

Interactive Discussion 


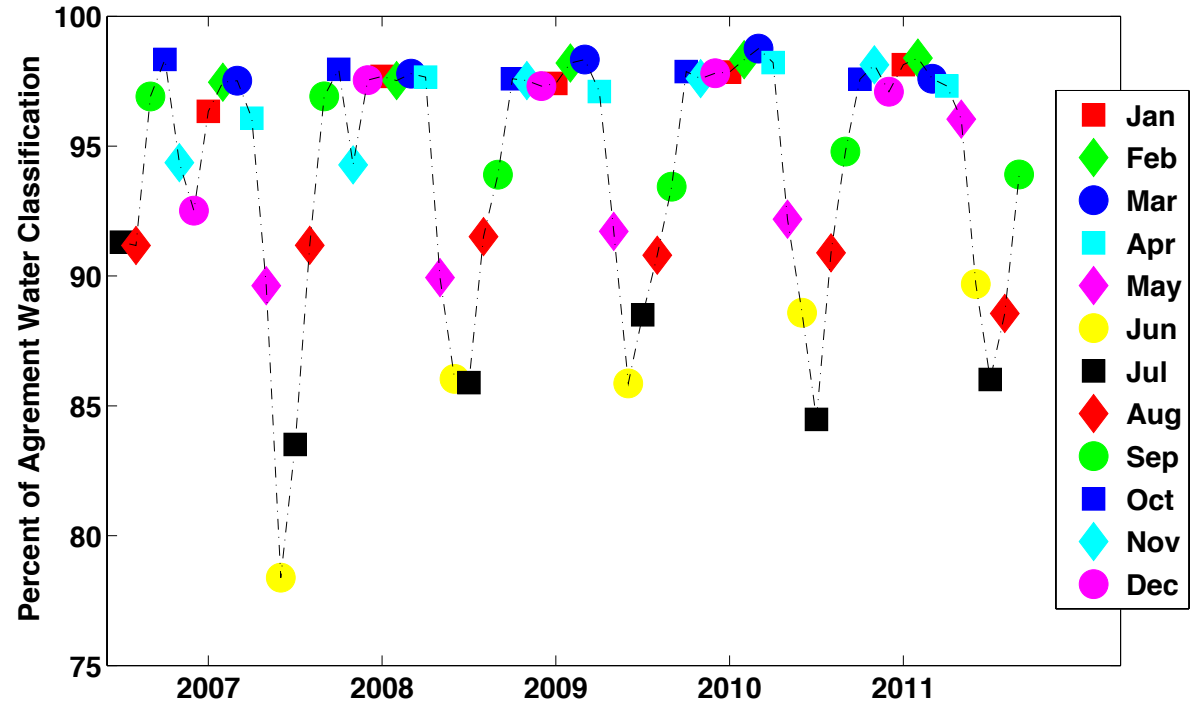

Fig. 4. Northern Latitudes for 2006 to 2011 monthly percentage of occurrence when AMSR-E classified the pixel as water, the calculated depolarization values fell in the range of 0.0 to 0.02 .
TCD

$7,4681-4701,2013$

Sea ice detection with space-based LIDAR

S. Rodier et al.

Title Page

Abstract Introduction

Conclusions References

Tables Figures

14 $>1$

4

Back

Close

\section{Full Screen / Esc}

Printer-friendly Version

Interactive Discussion 


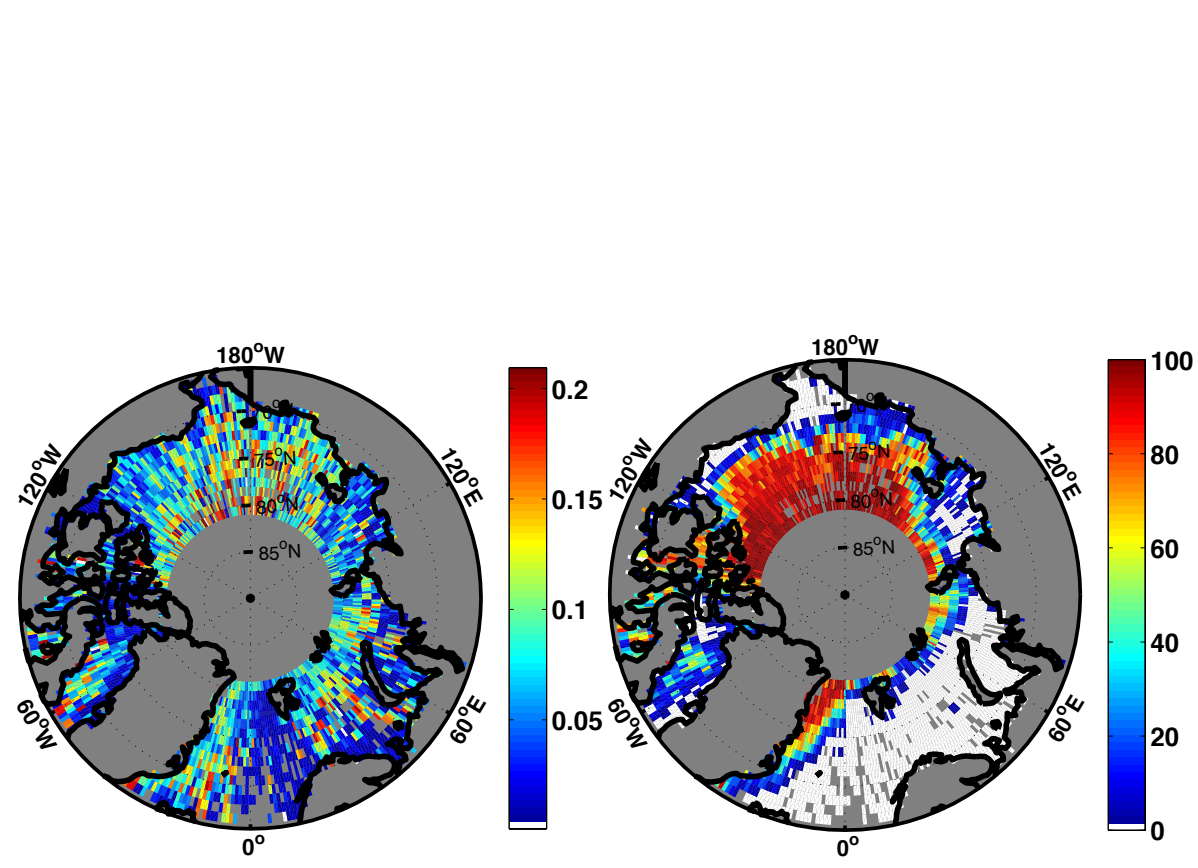

Fig. 5. (a) The CALIOP footprints for July 2011 with depolarization values less than 0.2 , and thus classified as water. (b) The AMSRE classification for the collocated pixel. The AMSRE plot ranges from 100 percent ice, seen in dark red, to zero percent ice, or water, which is represented as white.

\section{TCD}

$7,4681-4701,2013$

\section{Sea ice detection with space-based LIDAR}

\section{S. Rodier et al.}

\section{Title Page}

4

\section{Full Screen / Esc}

Printer-friendly Version

Interactive Discussion 


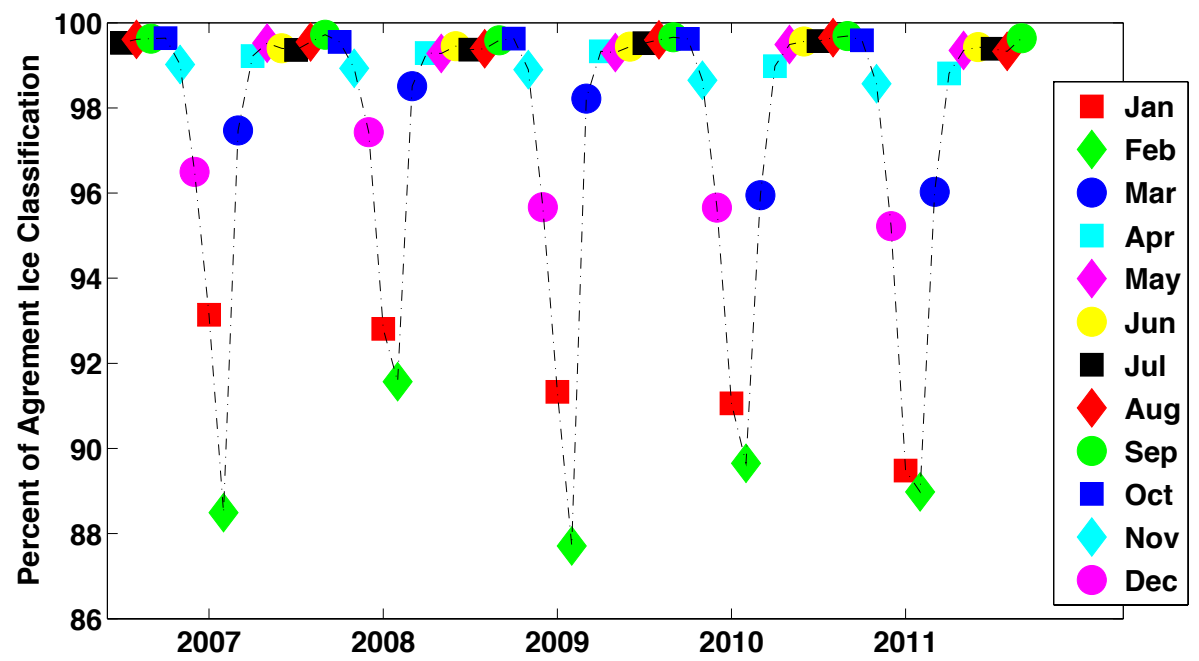

TCD

7, 4681-4701, 2013

Sea ice detection with space-based LIDAR

S. Rodier et al.

Title Page

Abstract

Conclusions

Tables

14

4

Back

Fig. 6. Southern Latitudes for 2006 to 2011 monthly percentage of agreement when AMSR-E classified the pixel as ice, the calculated depolarization values fell in the range of 0.55 to 1.1 .

Printer-friendly Version

Interactive Discussion
References

Figures

$\rightarrow 1$

$>$

Close

Full Screen / Esc

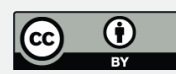




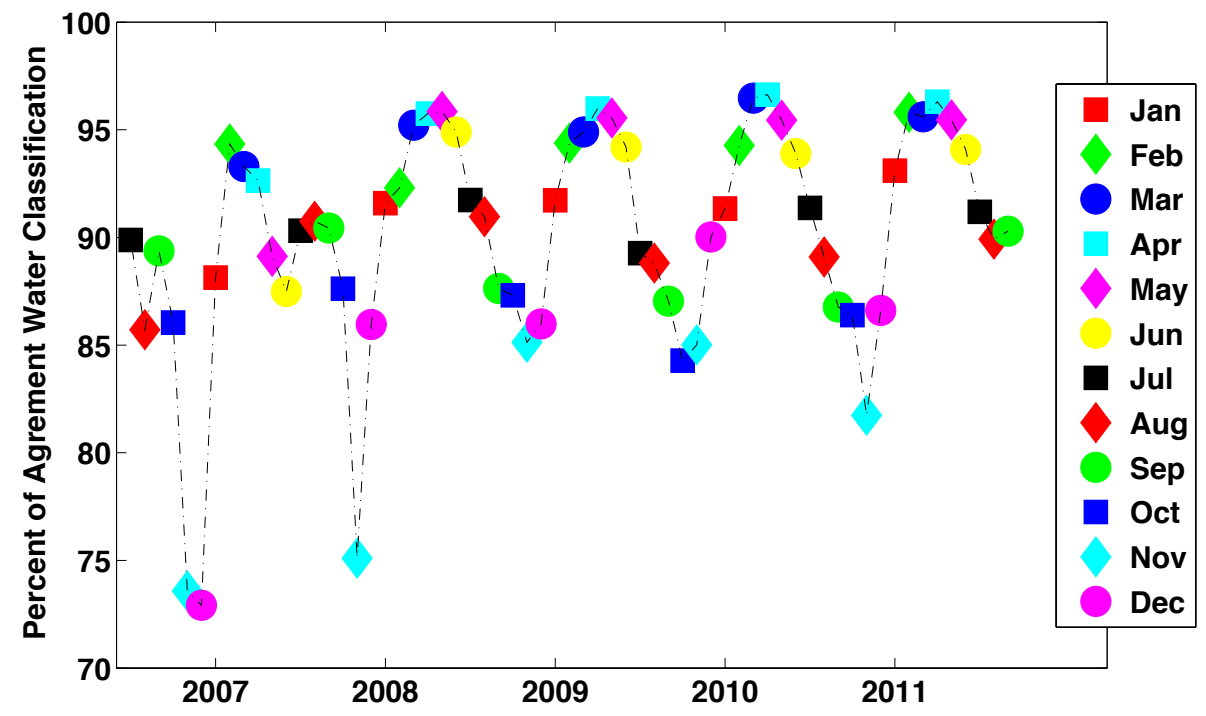

Fig. 7. Southern Latitudes for 2006 to 2011 monthly percentage of occurrence when AMSR-E classified the pixel as water, the calculated depolarization values fell in the range of 0.0 to 0.02 .
TCD

7, 4681-4701, 2013

\section{Sea ice detection with space-based LIDAR}

S. Rodier et al.

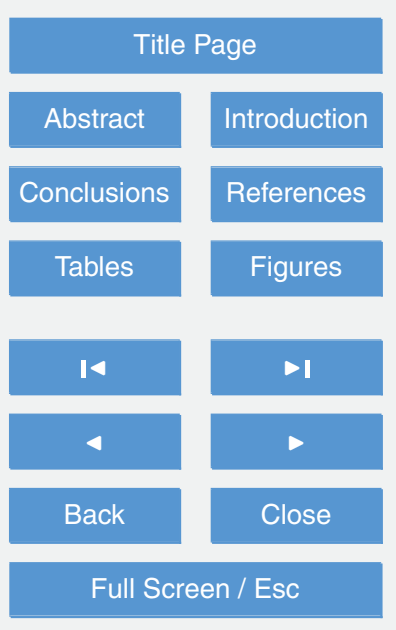

Printer-friendly Version

Interactive Discussion 